\title{
THE PERINATAL AND MATERNAL OUTCOME IN PREGNANCY WITH ADVANCED MATERNAL AGE 35 YEARS AND >35 YEARS IN WESTERN RAJASTHAN
}

\section{Obstetrics \& Gynaecology}

Dr Sangeeta*

$3^{\text {rd }}$ year resident Department of obstetrics and gynecology umaid Hospital, Dr S N Medical college, Jodhpur *Corresponding Author

Dr Kalpana Mehta

Sr Professor \& unit head Department of obstetrics and gynecology umaid Hospital, Dr S N Medical college, Jodhpur

\section{Dr Vimla \\ Choudhary}

\section{Dr Vinod}

Assistant professor Department of obstetrics and gynecology umaid Hospital, Dr S N Medical college, Jodhpur

$3^{\text {rd }}$ year resident Department of obstetrics and gynecology umaid Hospital, Dr S N Medical college, Jodhpur

$2^{\text {nd }}$ year resident Department of obstetrics and gynecology umaid Hospital, Dr S N Medical \section{college, Jodhpur \\ ABSTRACT \\ BACKGROUND Pregnancy is affected by maternal age from conception till delivery. Various studies have been conducted globally to study this effect; few in developing countries. It is associated with decreased fertility and increased risk. Simultaneously higher advanced technique and better supported maternal and neonatal care also exist. Maternal age is increasing in developing countries as well, so we have conducted this study. METHOD: It is observational prospective analytic study, conducted in umaid hospital, Dr S N medical college ,jodhpur. Total 322 patients were included in study, fulfilling inclusion criteria over period of 6 months. RESULT : A total no. of 322 elderly pregnant patients were selected for the study. Most of the cases were in the age group 35 to 39 years ( $89.93 \%)$. Multi gravida (71.8\%) and grand multi para $(22.22 \%)$ constituted the largest group. Most of the cases belong to lower socio-economic status (90\%). Percentage of unbooked cases was $82.98 \%$. The causes of delay in pregnancy were preference for male child $(25.1 \%)$ and unawareness of contraception $(22.36 \%)$. The incidence of diabetes mellitus and chronic hypertension were increased. Overall caesarean rate was increased $(35.4 \%)$. Incidence of abortions $21(6.5 \%)$, preterm delivery $18(5.6 \%)$, oligohydramnios 20(6.21\%), APH 9(2.8\%) and PROM 16(4.96\%), low birth weight baby 33(10.25\%), NICU admission 18 (5.6\%), IUGR $14(4.34 \%)$ all were high. The preference for male child $81(25.1 \%)$ and lack of awareness $72(22.36 \%)$ were two major reason for continuing pregnancies and deliveries till late age. CONCLUSION The present study showed that pregnancy at advanced age is a higher risk pregnancy in term of increased maternal and perinatal morbidity and mortality.}

DrAnusha

\section{KEYWORDS}

Advanced maternal age, Elderly gravida, Maternal and perinatal outcome.

\section{INTRODUCTION}

According to Williams obstetrics the term advanced maternal age, is defined as age 35 years or more for the mother at the time of delivery of her baby. The definition of advanced maternal age varies from study to study with most of earlier reports fixing the cut off points at 35 years and more recent one around 40 years. ${ }^{1}$ Globally, there is a rising trend among women towards delaying pregnancy and childbirth. This is due to educational status, professional goals, easy access to wide range of modern contraceptive methods and availability of assisted reproductive technology.

Becoming pregnant after the age of 35 years can present a challenge because of the maternal risk factors associated with it, such assubfertility, miscarriages, pre-eclampsia, gestational diabetes mellitus, anemia, intrauterine growth restriction, antepartum hemorrhage, higher incidence of instrumental deliveries, caesarean section, post-partum hemorrhage and fetal risk factors such as; malpresentation, multiple pregnancy, prematurity, increased NICU admissions due to increased perinatal morbidity and mortality.

Studies have been conducted globally to analyze the effects of advanced maternal age on pregnancy outcome. As the number of women with advanced maternal age has also been increasing in developing countries like ours, we conducted a prospective observational study to evaluate the pregnancy outcomes in women aged 35 years and above

\section{METHODS}

\section{Inclusion criteria}

All pregnant women age 35 years or above 35 years with

1. Single/multiple pregnancy

2. Mother with any pre-existing medical history i.e. hypertension, pregnancy induced hypertension, diabetes mellitus, gestational diabetes militias, anaemia, fibroids etc.

3. Conceived spontaneously/after treatment.
This study initiated only after the ethics committee permission. This is prospective observational study, conducted in umaid hospital, Dr S N medical college, jodhpur. 322 patients fulfilling the inclusion criteria were enrolled. Signature and consent of the patient taken at the time of study. At any point of the study if the patient fell short of the laid criteria she was omitted from the study and the next patient taken. Each one of them was evaluated by detailed history which included the menstrual, obstetric and clinical examination. Patient was followed up once monthly till 28 weeks, once fortnightly till 36 weeks and weekly there after till term. More frequent visits in high risk pregnancies like HDOP, GDM, D.M, primary infertility etc. We observed the effect of advance maternal age on fetal growth closely.

1. Patient who had registered in first trimester were subjected to - USG for NT and NB, Dual marker biochemical study.

2. In 2nd trimester or who registered in 2 nd trimester (before $20 \mathrm{wk}$ ) were subjected to malformation scan, triple marker or Quadruple biochemical screening. After 20 weeks of gestations-only malformation scan was performed. Patient showing high risk in above screening test were managed according to routine obstetrics protocol. The patients were followed up to the delivery and 4 days postdelivery.

Exclusion criteria were all pregnant woman admission below the age of 35 years, patients coming for medical termination of pregnancy even if they were more than thirty-five years of the age, patients not willing for participation in the study, patients with Chronic renal failure, severe cardiac disease, chronic liver disease, chronic lung disease like pulmonary tuberculosis and COPD etc.

Perinatal outcome was recorded in terms of birth weight, any chromosomal abnormalities, gestational age of delivery, NICU admission. Maternal outcome was recorded in terms of mode of delivery, obstetric complication, and systemic complications. 
RESULT

RESULTS It was observed that Majority $89.93 \%$ patient were from age group of 35 year to 39 years. Only $2.08 \%$ were found above the age of 45 cases are from at and above 45 year.

Table 1: Cause of delay in pregnancy.

\begin{tabular}{|c|c|c|}
\hline Causes & No. & Percentage \\
\hline Preference for male child & 81 & 25.1 \\
\hline Late marriages & 10 & 3.1 \\
\hline infertility & 14 & 4.35 \\
\hline Unawareness & 72 & 22.36 \\
\hline unknown & 145 & 45 \\
\hline
\end{tabular}

Analysis of parity status shows that $71.87 \%$ patient were Multi gravida and $22.22 \%$ are Grand multi gravid only $5.9 \%$ patient were primigravida. Maximum patient $(92.91 \%)$ belong to lower Socioeconomic status. Only $1.7 \%$ patient were from upper socio-economic class, $5.0 \%$ cases belong to upper middle and $55.55 \%$ belong to lower middle class. Almost two third of the patients $(65.97 \%)$ were from urban areas and $34.03 \%$ were from rural areas. Majority of the cases were unbooked (82.98) only $17.02 \%$ cases were booked for antenatal care. Observation of Causes of Delay in pregnancy reveals that preference for male child $(23.95 \%)$ and lack of awareness $(21.52 \%)$ were two major reasons for delaying pregnancy and delivery till late age (Table 1).

Table 2: Pregnancy outcome.

\begin{tabular}{|c|c|c|}
\hline Outcome & No. & Percentage \\
\hline LSCS & 114 & 35.4 \\
\hline Vaginal delivery & 180 & 55.9 \\
\hline Abortion & 21 & 6.5 \\
\hline Laparotomy & 7 & 2.2 \\
\hline
\end{tabular}

Analysis of pregnancy outcome reveals that half $(55.9 \%)$ of the patients delivered vaginally, $35.4 \%$ underwent LSCS, $6.5 \%$ underwent suction and Evacuation for abortion, Laparotomy were performed in $2.2 \%$ for ectopic pregnancy (Table 2 ).

Table 3: Pregnancy complications.

\begin{tabular}{|c|c|c|}
\hline Outcome & No. & percentage \\
\hline HDOP & 16 & 4.96 \\
\hline GDM & 9 & 2.8 \\
\hline Abortion & 21 & 6.52 \\
\hline Ectopic & 7 & 2.2 \\
\hline Preterm & 18 & 5.6 \\
\hline Oligohydramnios & 20 & 6.21 \\
\hline Malpresentation & 13 & 4.03 \\
\hline Twin & 7 & 2.2 \\
\hline Prom & 16 & 4.96 \\
\hline APH & 9 & 2.8 \\
\hline PPH & 16 & 4.96 \\
\hline uneventful & 170 & 52.7 \\
\hline
\end{tabular}

In the present study it was observed that $52.7 \%$ patient had uneventful outcome. Remaining patient had complication including abortion $(6.52 \%)$, Ectopic Pregnancy $(2.2 \%)$, hypertensive disorder of Pregnancy (4.96\%), Preterm Delivery (5.6\%), Oligohydramios (6.21\%), Malpresentation (4.03\%), Twin Delivery (2.2\%), Premature rupture of membrane $(4.96 \%)$, Antepartum haemorrhage $(2.8 \%)$ and Postpartum hemorrhage (4.96\%) (Table 3$)$.

Table 4: Perinatal outcome.

\begin{tabular}{|c|c|c|}
\hline Outcome & No. & Percentage \\
\hline Congenital anomaly & 5 & 1.55 \\
\hline Low birth weight & 33 & 10.25 \\
\hline IUGR & 14 & 4.35 \\
\hline NICU admissions & 18 & 5.6 \\
\hline Fetal demise & 4 & 1.24 \\
\hline Uneventful & 248 & 77 \\
\hline
\end{tabular}

Perinatal outcome was uneventful in $77 \%$ of patients. Congenital anomaly was seen in $1.55 \%$ of babies, $10.25 \%$ of neonates were Low Birth Weight baby, 5.6\% required NICU admissions, Intrauterine Death was seen in $1.24 \%$, and Intra Uterine Growth Retardation were
$4.35 \%$ (Table 4$)$

\section{DISCUSSION}

The objective of this report is to provide an update of our current knowledge about the impact of maternal age on pregnancy outcome. Pregnancy in women 35 years old is associated with a higher maternal and perinatal mortality.

Maximum number of cases are multigravida $71.87 \%$ and grand multipara $22.22 \%$ this is because of high fertility and large family size trends in India. Study conducted by Priyadatt. D. Patel mentioned the percentage of multigravida was 97.10 . Which is comparable to present study $(94.09 \%)$. grandmultipara group explains that large family size trend is still continued in India, particularly among women of low socio-economic status and low education qualification.

The older gravida also has a higher chance of being delivered by Caesarean section. In present study caesarean section rate was $35.4 \%$ In studies conducted by Vidaver J et al, Usha IM et al, cesarean rate was $38.8 \%$, Khalil et al 29.7\%, Giri et al 30\%, Powde Anuya A 35\%. So results are comparable to present study.7,8 Studies consistently show that women above 35 year of age are more likely than younger women to be delivered by caesarean (Bayrampur and Heaman). 9 There is almost linear increase in relationship between maternal age and uterine dysfunction in a continuous effect throughout the child bearing years as reported by Main et al, Greenberg et al, Treky et al. ${ }^{10,11,12}$

With increasing age the rate of spontaneous conception reduced Moreover, the likelihood of a successful response to ovarian stimulation resulting in egg retrieval decreases as the woman ages and this, compounded by the fact that older women have a poor ovarian response, makes women aged 35 years or older less than ideal candidates for ARTs. In our study incidence of infertility was ${ }^{4.35}$

The most important effect of ageing on the cardiovascular system is a gradual loss of compliance. Thus the normal hemodynamic adaptation to pregnancy becomes more difficult with advancing age. Thus incidence of hypertension is more common in this age group. In our study incidence of pregnancy induced hypertension was $4.96 \%$

In our country due Social and cultural reasons and lack of education and awareness. 13 Women continue to produce children right from the beginning till the end of their reproductive career. Fertility decreases, and rate of miscarriage increases with advancing maternal age..$^{14,15,16}$

In present study incidence of diabetic mellitus was $2.8 \%$. Which is comparable to Study done by Giri et al. 1.1\%, Rehman et al, $1.96 \%$. Khalil et al. $2.4 \% .13,17$ In present study incidence of hypertensive disorder of pregnancy was $4.96 \%$ which is comparable to study done by Giri et al, 2.2\%, Benil et al, 5.2\% and Meenakashi et al, 2.2\%

Present study show percentage of PPH $4.96 \%$. The incidence of Postpartum hemorrhage is higher advance maternal age because atonicity as a result of multiparity and poor myometrial function. ${ }^{8,18}$

This study shows incidence of Preterm delivery as high as $5.6 \%$. Study done by Benli et al, have $5.8 \%$, are comparable to present study. The incidence of preterm delivery increases because of iatrogenic cause associated with advanced maternal age are chronic hypertension and diabetes mellitus and Antepartum hemorrhage. Malpresentation, twin pregnancy were also cause of preterm delivery in advance maternal age.

In present study major cause of advanced maternal age are desire for male child that is $25.1 \%$ and unawareness contraceptives $22.3 \%$.

Incidence of IUGR was $4.35 \%$ in current study which is comparable to study done by Khalil et al, $4.7 \%$. Advancing maternal age is associated with a decrease potential for foetal growth possibly reflecting biologic ageing of maternal tissue and systems or the cumulative effects of diseases Leeks et al.

\section{CONCLUSION}

Pregnancy and delivery are never risk-free. As obstetricians and gynaecologists, we have a duty to address the growing epidemic of aging motherhood and the complications that arise from this, as well as to inform women of the risks associated with delayed childbearing. 
1. A proper preconception consultation and intensive antenatal care assessment can individualize and potentially reduce the risks for women considering a pregnancy at any age.

2. The rising trends of obstetric complications was observed in patients $>35$ years of age so this group of patients should be considered as one of the obstetric highrisk category and they need special attention and vigilant care in the multidisciplinary tertiary care centre.

3. With higher incidence of chromosomal abnormalities, women $\geq 35$ years of age should be offered screening for fatal aneuploidy. With availability of non-invasive, sensitive biochemical tests in combination with nuchal scan, need for invasive procedures greatly reduced.

4. There is rising trend of caesarean section in advanced maternal age due to increased incidence of pregnancies following ARTs, multiple pregnancies, pregnancy complicated by medical disorders and the physician's attitude contributes to the higher rate of Caesarean births in older gravidas by considering them to be at high risk or their pregnancies to be more precious.

\section{REFERENCES}

1. Salihu HM, Shupert MN, Slay M, Kirby RS, Alexander GR. Childbearing Beyond Maternal age 50 and fetal outcomes in the united states. J Obstet Gynecol. 2003;102:1006-4.

2. Ramachandran N, Sethuraman D, Nachimuthu V, Natarajan T. Obstetric and perinatal outcome of elderly mothers aged 35 years and above: a comparative study. Int J Res Med Sci. 2015;3(1):214-9.

3. Cleary-Goldman J, Malone FD, Vidaver J, Ball RH, Nyberg DA, Comstock CH, et al. Impact of maternal age on obstetric outcome. Obstet Gynecol. 2005;105(5.1):983-90.

4. Zahan UM, Suchi FA, Shampi SB, Husan GWMZ. Feto-maternal out-come of advanced maternal age-a clinical study in BSMMU.IOSR J Dent Med Sci. (IOSR-JDMS). 2013;9(5):76-80

5. Pawde AA, Kulkarni MP, Unni J. Pregnancy in women aged 35 years and above: a prospective observational study. J Obstet Gynaecol India. 2015;65(2):93-6.

6. Priyadatt D Patel, Shital T Mehta, Babu S. Patel Advanced maternal age; facts, factors and fetomaternal outcome. Int J Sci Res.2016;5(1):2277-8179.

7. Seoud M, Nassar A, Usta I, Melhem Z, Kazma A, Khalil A. Impact of advanced maternal Seon

8. Pawde AA, Kulkarni MP, Unni J. Pregnancy in women aged 35 years and above: A prospective observational study. J Obstet Gynecol India. 2015;65(2):93-6.

9. Bayrampour H, Heaman M. Advanced maternal age and the risk of caesarean birth: a systematic review. Birth. 2010;37(3):219.

10. Main DM, Main EK, Moore DH 2nd. The relationship between maternal age and uterine dysfunction: a continuous effect throughout reproductive life. Am J Obstet Gynecol 2000; 182(6): 1312

11. Greenberg MB, Cheng YW, Sullivan M, et al. Does length of labour vary by maternal age? Am jobstet gynecol 2007; 197(4):428.e1.

12. Treacy A, Robson M, O'Herlihy C. Dystocia increases with advancing maternal age. Am Jreacy A, RobsonM, O'Herlihy C. Dys

13. Najah Abdul Rehman, Archana Vikram, Najma Palakki, Nada Chettian Kandy. Maternal and fetal outcome in advanced maternal age. J of Evolution of Med and Dent Sci. 2015;4(6):2278-4748

14. National Center for Health Statistics. Birth rate for women aged 15-44

15. Centers for Disease Control. Assisted Reproductive Technology (ART) Report2002 National Summary (Accessed 5/5/05).

16. Tietze C. Reproductive span and rate of reproduction among Hutterite women. Fertil Steril 1957;12(5): 89-97

17. Khalil A, Yngelaki A, Maiz N, Zinevich Y, Nicoladies KH. Maternal age and adverse pregnancy outcome: a cohort study. Ultrasound Obstet Gynecol 2013;42(6):634-43

18. Amarin VN, Akasheh HF. Advanced maternal age and pregnancy outcome. East Mediterr Health J. 2001;7(4-5):646-51

19. Leeks KS, Ferguson RM, Corpuz $\mathrm{M}$ et al. Maternal age and incidence of low birth weight at term: a population study. Am J Obstet Gynecol 1988;158(1):84-9. 